\title{
Transcription Factor RelB
}

National Cancer Institute

\section{Source}

National Cancer Institute. Transcription Factor Re/B. NCI Thesaurus. Code C105999.

Transcription factor RelB (579 aa, $\sim 62 \mathrm{kDa}$ ) is encoded by the human RELB gene. This protein is involved in transcriptional regulation of immune processes. 